\title{
An Egalitarian-BicaudalD complex is essential for oocyte specification and axis determination in Drosophila
}

\author{
Jennifer M. Mach ${ }^{1,4}$ and Ruth Lehmann ${ }^{1-3}$ \\ ${ }^{1}$ Whitehead Institute for Biomedical Research and Department of Biology, Massachusetts Institute of Technology, \\ Cambridge, Massachusetts 02142 USA; ${ }^{2}$ Skirball Institute for Biomolecular Medicine, New York University Medical Center, \\ New York, New York 10016 USA
}

Genetic experiments suggest that polarization of the oocyte is linked directly to the initial cell fate determination that singles out the oocyte from its 15 sister cells. Specification of oocyte cell fate as well as establishment and maintenance of a polarized microtubule network within the Drosophila oocyte require the activity of the egalitarian (egI) and BicaudalD (BicD) genes. We have isolated the egl gene and show that Egl protein colocalizes with BicD protein at all stages of oogenesis. Immunoprecipitation experiments show that both proteins are part of a protein complex. Egl and BicD proteins localize to the oocyte in three stages that correlate with the stepwise polarization of the oocyte. We propose that the Egl-BicD protein complex links microtubule polarity and RNA transport. During early oogenesis, the complex is required to transport factors promoting oocyte differentiation; during later stages of oogenesis the complex directs the sorting of RNA molecules required for anterior-posterior and dorsoventral patterning of the embryo.

[Key Words: Drosophila; oocyte; oogenesis; cell polarity; RNA localization; microtubules; microtubule organizing center; egl; BicD]

Received December 3, 1996; revised version accepted January 10, 1997.

Pattern formation in the Drosophila embryo is controlled by the differential localization and activation of maternal gene products in the egg cytoplasm. The biological significance of this cytoplasmic asymmetry is best demonstrated by the localization of bicoid and oskar RNAs to the anterior and posterior poles of the growing oocyte and the effect of these two genes on anterior and posterior patterning of the embryo, respectively ( $\mathrm{St}$ Johnston and Nüsslein-Volhard 1992). Little is known about the molecular mechanisms that control polarization of the oocyte cytoplasm. Genetic experiments have suggested that establishment of polarity is linked to the determination of oocyte cell fate (González-Reyes et al. 1994; Lin and Spradling 1995).

How one cell becomes the oocyte from a cluster of genetically identical cells is not well understood. The Drosophila oocyte forms after four synchronous cell divisions that form a cluster of 16 cells interconnected by cytoplasmic bridges called ring canals. One of these cells becomes the oocyte; the other 15 form polyploid feeder cells, the nurse cells. A bias toward the oocyte fate already may be set during the first division of the oocyte

${ }^{3}$ Corresponding author.

E-MAIL lehmann@saturn.med.nyu.edu; FAX (212) 263-7760.

${ }^{4}$ Present address: Department of Molecular, Cellular and Developmental Biology, University of Colorado at Boulder, Boulder, Colorado, 80309. 0347. precursor, or cystoblast, when one daughter inherits the spectrosome, a spectrin-rich organelle that seems to play a role in orienting the plane of division of the cystoblast progeny (Lin and Spradling 1995). Asymmetric segregation of the spectrosome may be the basis for oocyte determination. In hu-li tai shao (hts) mutants, which lack the spectrosome, the germ cells divide abnormally and rarely produce an oocyte (Yue and Spradling 1992; Lin et al. 1994).

Failure to designate one cell as the oocyte leads to the development of all 16 cells as polyploid nurse cells. In flies mutant for the BicaudalD (BicD), egalitarian (egl), or stonewall (stwl) genes, the cystoblast divisions occur normally, but the cell that would become the oocyte instead becomes a sixteenth nurse cell (Suter et al. 1989; Wharton and Struhl 1989; Schüpbach and Wieschaus 1991; Ran et al. 1994; Clark and McKearin 1996). BicD encodes a protein with a predicted coiled-coil structure (Suter et al. 1989; Wharton and Struhl 1989). BicD protein localizes to the oocyte in early oogenesis, immediately after the formation of the 16-cell cluster. stwl encodes a predicted transcription factor that localizes to the germ cell nuclei in all 16 cells /Clark and McKearin 1996). In stwl mutants, BicD protein is present but unlocalized.

In addition to $B i c D, e g l$, and stwl, microtubules have been implicated in oocyte determination. Treating wildtype flies with microtubule-depolymerizing drugs such 
as colchicine can cause a 16-nurse-cell phenotype (Koch and Spitzer 1983; Theurkauf et al. 1993). Also, a microtubule organizing center (MTOC) forms in the presumptive oocyte just after the formation of the 16-cell cluster; in BiCD mutants this MTOC does not form (Theurkauf et al. 1993). Because BicD protein localizes to a single cell in one of these BicD alleles, BicD can localize without the formation of an MTOC. Localization of BicD to a single cell may thus initiate the asymmetry that leads to the formation of the MTOC in one cell, the future oocyte. In egI mutants the MTOC forms and then immediately dissipates, suggesting that BicD and egl act sequentially and that egl may play a direct role in oocyte specification.

To reveal the molecular basis of oocyte determination, we cloned the egl gene. We show that Egl protein and BicD protein colocalize during oogenesis. Initially, both proteins accumulate in the future oocyte; they then concentrate at the posterior cortex of the oocyte before they localize transiently to the anterior margin of the oocyte. At each step the localization pattern resembles that of the presumed minus ends of microtubules. Immunoprecipitation experiments demonstrate that Egl and BicD are part of a protein complex. Analysis of mutations in egl and BicD suggests that this complex is required for the specification of the oocyte and the establishment of oocyte polarity.

\section{Results}

egl mutations affect oocyte determination

Drosophila oocytes are produced in strings of maturing egg chambers, the ovarioles (Fig. 1D; for review, see King
1970; Spradling 1993). At the anterior tip of each ovariole, in the germarium, stem cells divide to produce a cystoblast and a new stem cell. Each cystoblast undergoes four rounds of mitosis, thereby generating a 16-cell cyst. At each division, incomplete cytokinesis produces an actin-rimmed cytoplasmic bridge, the ring canal, which connects mother and daughter cells. Because all ring canal connections made previously segregate to one cell at each division, the two products of the initial cystoblast division have four ring canals; one of these two cells becomes the oocyte. At the end of the germarial region, the complete 16-cell cluster is surrounded by somatic follicle cells and the future oocyte moves to the posterior of the cluster. At this point the future oocyte and its sisters follow strikingly different fates: The oocyte arrests in prophase of the first meiotic division, whereas the remaining 15 cells continue to replicate their DNA and become polyploid nurse cells.

In $e g l$ mutants, cystoblast divisions proceed as in wild type (Lin et al. 1994). However, none of the cystoblast daughters develops as an oocyte and all 16 cells become polyploid nurse cells (Fig. 1, A and B, cf. nuclei indicated by arrows). Despite the lack of oocyte determination, the initial formation of the cluster proceeds normally and one of the cells with four ring canals is usually located at the posterior (Carpenter 1994). Further development of the 16-cell cluster ceases at about stage 6 of oogenesis, no cell accumulates yolk, and eventually the cluster degenerates.

Because the first signs of oocyte differentiation coincide with the association of somatic follicle cells with the 16-cell cyst, egl could act either in the germ line or in the soma to promote oocyte differentiation. To determine where egl functions, we generated chimeras of

Figure 1. egl phenotype. Confocal images of a single optical section through ovarioles stained for DNA in green (OliGreen), and filamentous actin, staining ring canals, in purple (BODIPY phalloidin). Anterior is to the left. (A) Wild-type ovariole showing the development of the oocyte. (G) Germarium to left; stage 10 egg chamber at right. The oocyte nucleus is visible as a small green dot in the posterior-most germ cell (arrow). The nurse cell nuclei are to the anterior and stain more brightly because of their higher DNA content. This image is a composite of three scans made in different focal planes to show the oocyte nucleus of each egg chamber. $(B) e g I^{W U 50}$ ovariole. All 16 cells, including the posterior-most cell, have polyploid nuclei of similar size. (C) Transplanted wild-type germ cells form normal oocytes (arrows) amid the background of endogenous egl mutant germ cells of the host. The genotype of normal germ cells was determined by progeny test. $(D)$ Cell types and stages of oogenesis (not to scale).
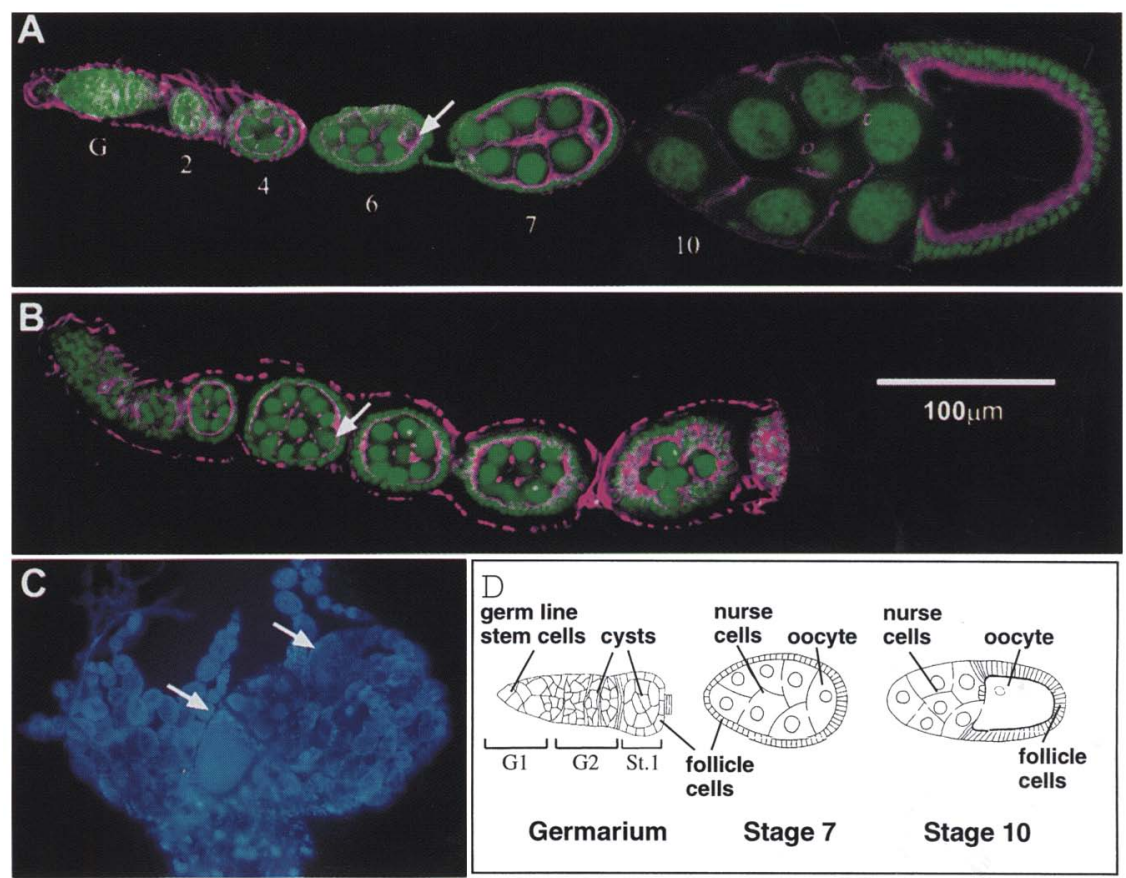
wild-type and mutant tissues by transplantation of pole cells, the germ-line precursors. Mosaic flies with a genotypically wild-type germ line and an egl mutant soma developed normal oocytes (Fig. 1C) that produced progeny bearing the genetic markers of the introduced germ cells. Conversely, when the germ line is egt $1^{-}$and the soma is egl', oocyte determination is blocked (see Materials and Methods). Thus, oocyte determination requires egl function in the germ line, but not in the surrounding somatic follicle cells.

\section{Molecular identification of the egl gene}

We isolated the egl locus by positional cloning. A series of overlapping cosmids spanning the $80-\mathrm{kb}$ region between the breakpoints of two chromosomal deletions defines the egl region (Materials and Methods). To identify candidates for the egl transcription unit within this region we made use of the observations that egl function is required in the germ line and that $e g I$ has a very similar phenotype to $B i c D$. Because both $e g l$ and $B i c D$ have a 16-nurse-cell phenotype and function in the germ line, we reasoned that egl RNA, like BicD RNA, might be localized to the developing oocyte very early during oogenesis. RNA blot analysis showed 16 ovarian transcripts in the egl region. By ovary in situ hybridization we found that two genomic fragments, $A$ and $B$, hybridize to RNA localized strictly to the developing oocyte in a pattern very similar to that of BicD mRNA. The A fragment hybridizes to a $4.6-\mathrm{kb}$ transcript and the B fragment hybridizes to $3.7-$ and $5.9-\mathrm{kb}$ transcripts (data not shown).

To determine whether one of these candidate RNAs could be encoded by the egl gene, we examined mutant egl alleles for changes in the size of each transcript. The 4.6-kb A transcript showed a slight increase in size in $e g l^{P B 23}$; the B transcripts are unaltered in all egl alleles (data not shown). To demonstrate that the A transcript encodes the $e g l$ gene product we complemented $e g l \mathrm{mu}$ tations with a transgene that expresses the A transcript. The transgene contained a $4.6-\mathrm{kb}$ cDNA that hybridizes to the A transcript and has a complete open reading frame (ORF). We fused this to the ovarian tumor promoter, which is expressed early during oogenesis (D. Robinson and L. Cooley, pers. comm.), and introduced it into flies by P-element-mediated transformation (Spradling 1986). We characterized a number of transgenic lines that show varying degrees of complementation, presumably as a result of their insertion site. Most lines fully complement the egl mutant phenotype such that egl homozygous flies carrying one copy of the transgene are fertile. We conclude that the A transcript corresponds to the egl transcript.

To analyze egl gene structure we sequenced the genomic DNA from the egl region and the $e g l \mathrm{cDNA}$ used to complement egl mutants (Fig. 2A). Conceptual translation of the 2.6-kb ORF starting at the AUG codon with the best match to the Drosophila consensus for initiation of protein synthesis (Cavener 1987) predicts an 874amino acid-protein (Fig. 2B). Comparison of the pre- dicted Egl protein to database sequences shows that Egl has significant similarity to the predicted gene product C10G6.1 from Caenorhabditis elegans (Wilson et al. 1994). The similarity lies in three blocks of $\sim 65$ amino acids each, with $46 \%$ identity. The third block, from amino acids 599 to 739 , also shows similarity to expressed sequence tags (ESTs) from Arabidopsis thaliana (58\% identity) and to ribonucleaseD from Haemophilus influenzae (38\% identity) (Zhang and Deutcher 1988). The significance of these similarities is unclear. The PAIRCOIL program (Berger et al. 1995) predicts a $67 \%$ probability that residues $744-775$ (bold in Fig. 2B) form a coiled-coil structure. A detailed analysis of Egl protein will be required to determine whether the observed similarities in protein sequences or structures to other proteins have functional significance.

To analyze the function of the Egl protein further, we generated antibodies against the amino-terminal half of the Egl protein (see Materials and Methods). The Egl antiserum detects a single band of $125 \mathrm{kD}$ in ovary extracts. Specificity of this antiserum for Egl is shown by two tests (Fig. 2C). First, the band detected on Western blots increases in intensity with increasing egl gene copy number. Second, Egl protein is not detected in extracts from several egl mutants. The lack of protein in these mutants cannot be explained by the failure of egl mutants to develop an oocyte, because Egl protein is detected in one egl mutant and two BicD alleles, all of which have a strong 16-nurse-cell phenotype (Fig. 2C).

To correlate protein structure with egl function we sequenced four strong egl mutant alleles; the coding alterations in these alleles are shown in Figure $2 \mathrm{~B}$ and described in Materials and Methods. Three mutations predict protein truncations (see Materials and Methods) and have no detectable Egl protein by Western blot or immunofluorescence (Figs. 2C and 5C); the phenotype of these alleles should reflect the egl null phenotype, which suggests that egl function is restricted to oogenesis. In contrast to these three protein truncation mutations, $e g 1^{4 e}$ has a single amino acid substitution, a cysteine to tyrosine change at amino acid 24. By immunoblotting with $\alpha$-Egl antiserum, we detect Egl protein in ovary extracts from $\mathrm{egl}^{4 e}$ mutants (Fig. $2 \mathrm{C}$ ). The $\mathrm{C} \rightarrow \mathrm{Y}$ change in $e g 1^{4 e}$ is in the first block of homology found between $e g I$ and C. elegans C10G6.1, suggesting that the similarities between these proteins may extend to function.

\section{egl $m R N A$ and protein localize within the oocyte}

Whole-mount in situ hybridization shows that egl mRNA is enriched in single cells when the 16-cell cyst forms in region 2A of the germarium (Fig. 3A). From stage 2 until stage 7 of oogenesis, egl RNA is concentrated at the posterior cortex of the oocyte. As the oocyte starts to accumulate yolk, egl transcript localizes in an anterior ring at the nurse cell-oocyte boundary. This distribution is similar to that of other RNAs, such as $K 10$, ool8 RNA-binding (orb), BicD, and oskar (osk), which accumulate early in the oocyte and form a transient anterior ring somewhat later (Suter et al. 1989; Ephrussi et 
Figure 2. The egl gene. $\langle A|$ Genomic organization of the egl locus. The egl locus comprises a 2.6-kb ORF, a $0.7-\mathrm{kb} \mathrm{5}$ ' UTR, and a $1.2-\mathrm{kb} 3^{\prime}$ UTR, interrupted by five introns. Narrow lightly shaded bars represent the noncoding regions, and darkly shaded bars represent the coding regions. The introns are represented by thin lines and are shown to scale, except for the second intron, which is 6 $\mathrm{kb}$. The predicted translation start site, CAAC, shows a four out of four match to the Drosophila translational initiation consensus $(\mathrm{C} / \mathrm{A}$ A A A/C; Cavener 1987). Three additional AUGs upstream of this site, AGCA, GTCC, and CGAG, show only limited matching to the consensus. The sequenced cDNA contains stop codons in all three reading frames upstream of this ORF and a polyadenylation site and poly $(A)$ tail in the $3^{\prime}$ UTR. $(B)$ Predicted sequence of $\mathrm{Egl}^{+}$and $e g l$ mutations. This sequence represents the conceptual translation of the large ORF in egl cDNA A9. Genomic DNA from $e g l$ alleles was sequenced from PCR products spanning the egl transcript. $(\nabla)$ Splice site mutations; (V) missense or nonsense mutations, with the predicted alteration and allele designation below. The putative coiled-coil, from amino acids $744-775$, is indicated in boldface type. Similarities to the C. elegans predicted gene product C10G6.1 are found from amino acids 1 to 50,105 to 149 , and 589 to 636. Similarities to an EST from $A$. thaliana and ribonucleaseD from $H$. influenzae and Escherichia coli are found from amino acids 592 to 639 and 675 to 699 . (C) Western blot analysis of Egl protein. For each lane, $\sim 8 \mu \mathrm{l}$ of dissected ovaries was lysed in an equal volume of boiling sample buffer, spun to remove insolubles, and loaded on an $8 \%$ acrylamide gel. For each egl allele, females were heterozygous for the allele and chromosomal deletion $D f(2 R) b w^{\text {s46 }}$; BicD alleles were heterozygous to $D f(2 L)$ TW119. After immunodetection of Egl protein, to normalize the amount of extract loaded, the blot was stripped in $2 \%$ SDS, $100 \mathrm{~mm}$ mercaptoethanol, $62.5 \mathrm{~mm}$ Tris- $\mathrm{HCl}$ at $\mathrm{pH} 6.8$ for $30 \mathrm{~min}$ at $65^{\circ} \mathrm{C}$. The blot was then reprobed with anti-Vasa antibody; this is shown below the Egl Western blot. The positions of the Bio-Rad high molecular weight size markers are indicated to the left. The 874-amino-acid product of the Egl ORF is predicted to migrate at $98 \mathrm{kD}$. However, the $\mathrm{Egl}$ protein, as detected by immunoblot analysis, migrates at $125 \mathrm{kD}$. The $\sim 50$ - and $\sim 75-\mathrm{kD}$ bands are likely unspecific because they are present in all $e g l$ mutants and are unaffected by $e g l$ gene dosage.

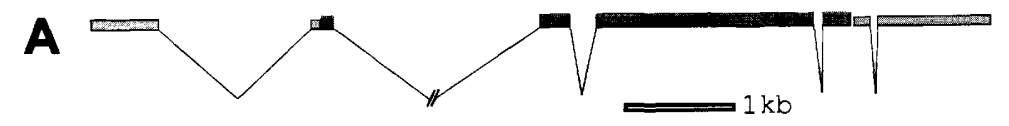

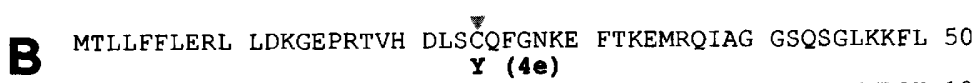
AQYPAIFLVD GDYVQVNAYQ HHNADDGGCG GKRDYIQEAK DYFKNKMLQY 100 GAAAEVPVRS LLGHRSQASP QVRHISGQHI KEFTDFLMKH TDTFKVTDDY 150 VMLVGCENMT DLPARDRLHL PQSNIDTRGT QQMLDFFAQC IEVKGPLLVD 200 QLFHLLTTNF PQDQWLRMFK TPGDLSSFLK LFADCFHIQA NLVTLLQKPK 250 LSDTHIQQAQ AQTREQFNAL NNNNSASIRK QEPTPGGGGV GGVSSVQQRL 300 STOP (PR29)
QSPALRTNGH TNNNNGSNGS NNNNNNNSI ACPNFKLNAP VSNVMGGQSQ 350 GFGQPKSEPS SGEDSYVPMS ELKLENLCEN NYPSANTCYG PINNSSQQÄ 400 QVQTQQQQQP QHATQNPAEQ RLNSVNQTLK QRINTLVIRT LAENLEKDKQ 450 SLANQQGGPI SPHASPVHSI ANSSSNQNAG SAANNANSNS NANPNNANHS 500 PSHSYFVGDT WKIKVLQNTT VIANVKQSVE VTDIILKYAA KNESIVVSLD 550 CEGINLGLKG EITLIEIGTT RGEAFLFDVQ SCPAMVTDGG LKTVLEHDQV 600 IKVIHDCRND AANLYLQFGI LLRNVFDTQA AHAILQYQES GKQVYKAKYI 650 SLNSLCEQYN APCNPIKDQL KQIYRRDQKF WAKRPLTREM MLYAAGDVLV 700 LIHDQLFGNL ARQIKPENRA LFSELCTEQI LMQIKPNEVK IRKRQRKVST 750 EVSDLKQKLA QTSKSIVLSN REIRLLRYMD LTEDEKERLK GYYKVAKKLE 800 KMESAGNPSK WVLSISNQIA IQLTTLFVLP EIKVTPRMNK SRTRTTPFPV 850 WIRCRRTTRF RAHFRHASVQ SHPA
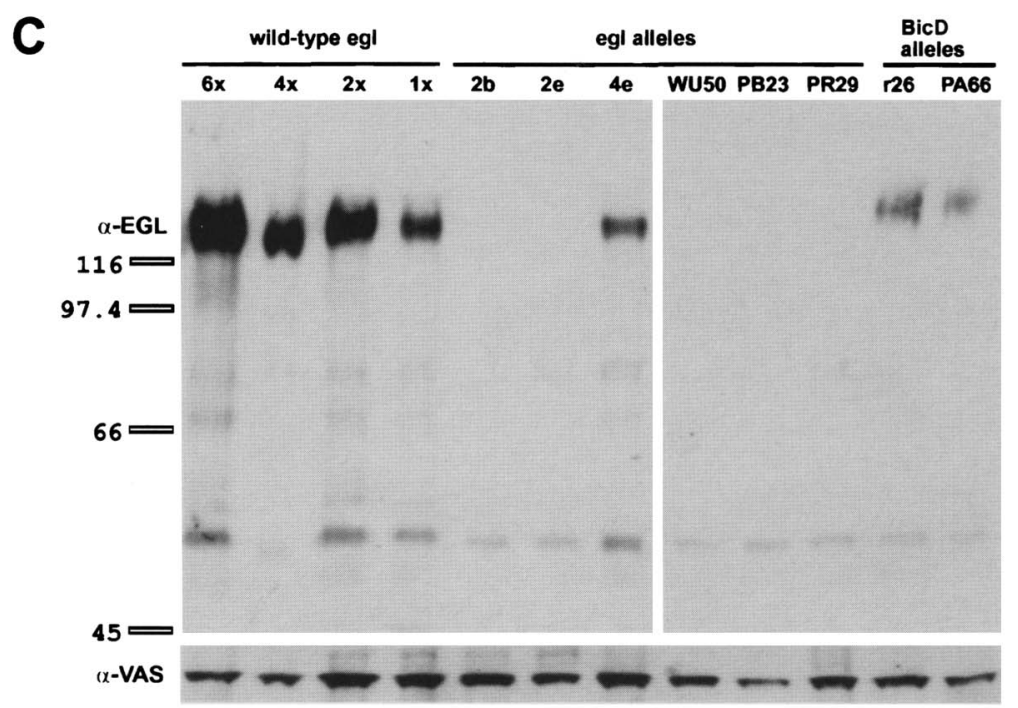

al. 1991; Kim-Ha et al. 1991; Cheung et al. 1992; Lantz et al. 1992). By stage 10 of oogenesis, egl RNA is distributed evenly throughout the oocyte but persists in the oocyte into early embryogenesis.

We used the anti-Egl antibody to determine where Egl protein is expressed during oogenesis. Egl protein is detectable in the germarium and initially is distributed evenly within the newly formed 16-cell cyst. Once the cyst flattens in germarial region $2 \mathrm{~B}$ the protein is often found concentrated in the two cells that have four ring canals (Fig. 3B). By stage 1 of oogenesis Egl protein localizes to a single cell, the future oocyte. From stage 2 to stage 7 of oogenesis, Egl protein is enriched at the posterior cortex of the oocyte, wherever the oocyte abuts the follicle cells. At stage 8 of oogenesis, Egl protein shifts to the anterior cortex in a ring around the margin of the oocyte where the oocyte, nurse cells, and follicle cells meet (Fig. 3C). Egl staining is especially pronounced 

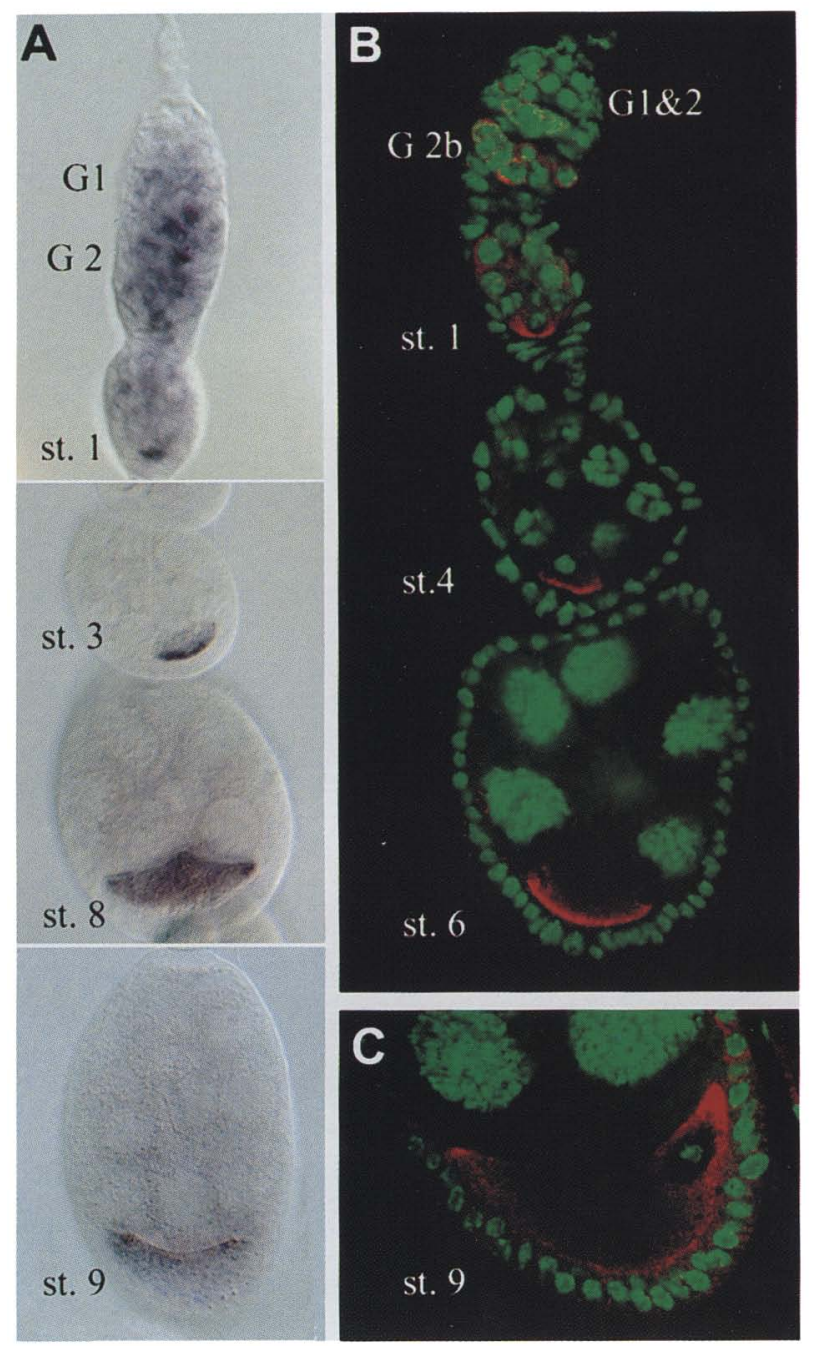

Figure 3. egl expression pattern. (A) egl mRNA localization. The full-length eg1 cDNA A9 was used as a template for synthesis of digoxigenin-labeled probe. The sample shown in the top panel was hybridized as described in Suter and Steward (1991), and the samples in the middle and bottom panels were hybridized as described in Ephrussi et al. (1991). The ovariole is oriented with the germarium up. $(B, C)$ Egl protein localization. The Egl protein is shown in red; DNA is shown in green. Rabbit anti-Egl antibody was used to detect Egl protein in wholemount ovaries, with Cy3 donkey anti-rabbit secondary (Jackson Labs|. DNA was stained with OliGreen (Molecular Probes). The ovariole shown in the top panel was assembled from three different scans taken at different focal levels on the Bio-Rad MRC 600 Confocal.

around the oocyte nucleus. We were unable to detect Egl protein by immunohistochemistry after stage 10 of oogenesis, although Western blot analysis shows that early embryos contain Egl protein (data not shown).

\section{Microtubules are required for Egl localization}

The distribution of Egl protein strikingly resembles the localization of the minus end of microtubules (Fig. 3B,C;
Theurkauf et al. 1992). During stages 1-6 of oogenesis, a microtubule network extends from an MTOC located at the posterior cortex of the early oocyte into the nurse cells. During stage 8 of oogenesis the microtubule network repolarizes and microtubules originate from the anterior cortex (Theurkauf et al. 1992). Microtubule function is important for oocyte determination. Treating wild-type flies with microtubule inhibitors causes a 16nurse-cell phenotype very similar to that of $e g l$ mutants (Koch and Spitzer 1983; Theurkauf et al. 1993). To test whether a polarized microtubule network is required for the Egl localization pattern, we treated flies with colchicine to disrupt microtubules and then examined the distribution of Egl protein. We used a short colchicine treatment so that the ovaries would contain some oocytes formed previously, allowing us to look at all stages of Egl protein localization. We find that disrupting microtubule organization abolishes Egl localization in the oocyte (Fig. 4). Thus, Egl localization requires microtubule organization. Moreover, it has been shown previously that in egl mutants the microtubule network, although established initially, is not maintained (Theurkauf et al. 1993). It is therefore likely that the effect of microtubules on oocyte determination is mediated by $\mathrm{Egl}$ and that Egl in turn reinforces or maintains the microtubule network after an initial polarity has been established.

\section{egl and BicD localization requires the function of both genes}

egl and BicD have very similar phenotypes: Both genes are essential for oocyte determination. Double-labeling experiments, in which the same egg chamber is stained for both Egl and BicD proteins, reveal that BicD and Egl proteins have identical distributions during all stages of oogenesis (Fig. 5A). To determine whether the localization of each protein requires the function of the other,

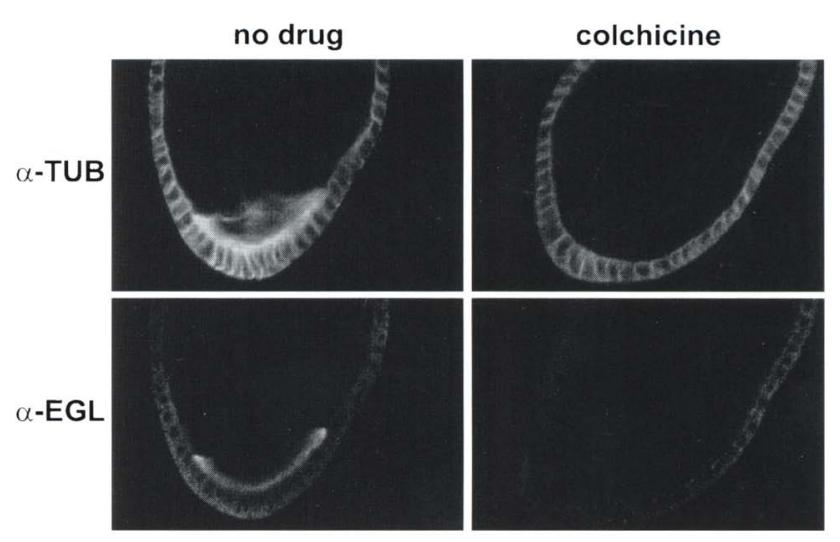

Figure 4. Egl, microtubules, and oocyte polarity. Microtubules are required for Egl localization. Ovaries were double-stained with anti-tubulin (top) and anti-Egl (bottom). Flies were either fed plain yeast paste (left) or yeast paste containing $50 \mu \mathrm{g} / \mathrm{ml}$ of colchicine (right) for $18 \mathrm{hr}$ before being dissected and stained. This treatment disrupts the germ-line microtubules without affecting the follicle cell microtubules. 


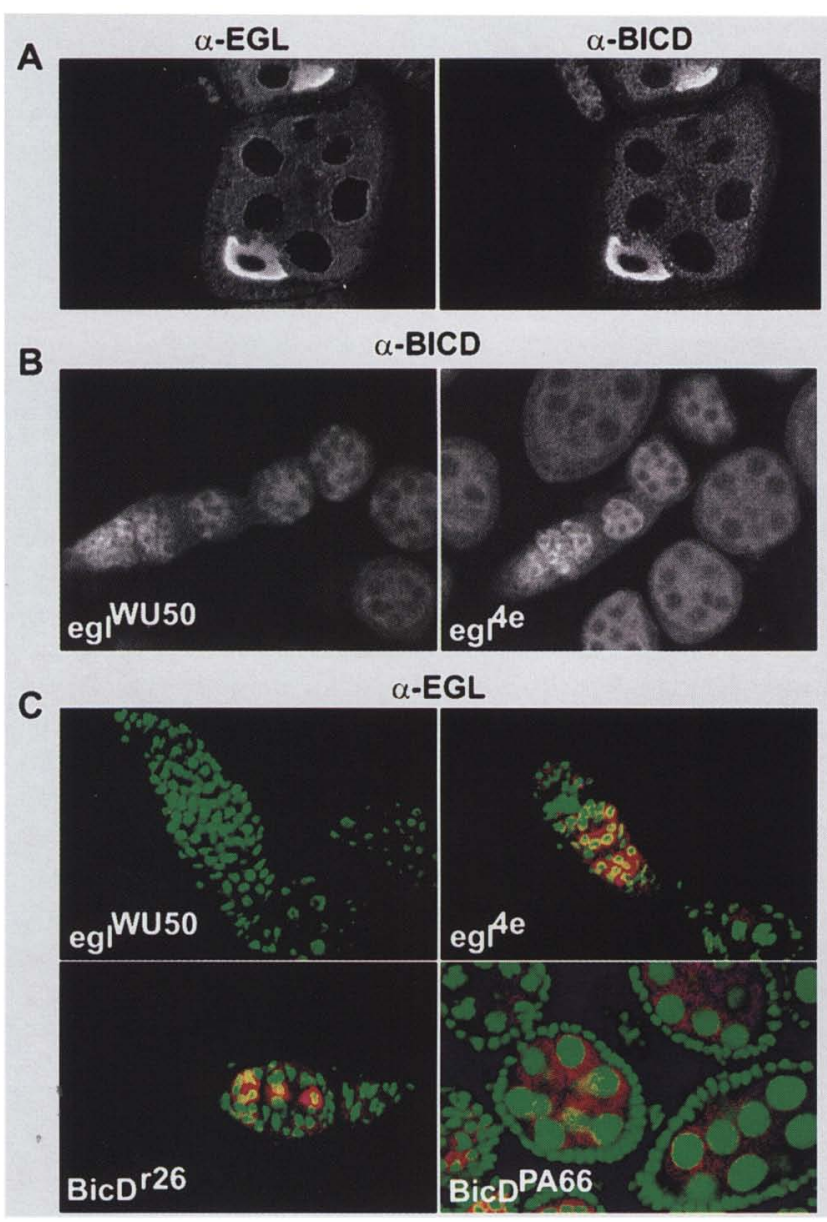

Figure 5. Localization of Egl and BicD. (A) Double staining for $\mathrm{Egl}$ and BicD. This sample was stained with both anti-Egl and anti-BicD. Anti-Egl was detected with Cy3 donkey anti-rabbit; BicD was detected with FITC donkey anti-mouse. To collect the image, the fluorescent tags were excited individually; no bleedthrough between channels was observed. $(B)$ BicD localization in egl mutants. BicD protein does not localize to a single cell in egl mutants. Each egl allele was used heterozygous to $D f(2 R) b w^{546}$. (C) Egl localization in egl and BicD mutants. Egl protein is shown in red; DNA is shown in green. No Egl protein is detectable in g $^{\text {WUSO }}$. Egl protein does not localize to a single cell in $e g l^{4 e}$ and $B i C D^{P A O \sigma}$; however, it does localize to a single cell in $B i c D^{26}$. For each $e g l$ allele, females were heterozygous for the allele and chromosomal deletion $D f(2 R) b w^{546} ; B i c D$ alleles were heterozygous to $D f(2 L) T W 119$.

we analyzed Egl and BicD distributions in mutant ovaries. We found that there is no hierarchical relationship between Egl and BicD localization; instead, localization of Egl depends on $B i C D$ and vice versa. For example, BicD does not accumulate in a single cell either in the absence of Egl protein $\left(e g I^{W U 5 O}\right)$ or in the presence of Egl mutant protein that fails to localize to a single cell $\left(\mathrm{eg} l^{4 e}\right)$ (Fig. $5 \mathrm{~B})$. Furthermore, in a BicD mutant where BicD protein does not localize $\left(B i c D^{P A 66}\right), \mathrm{Egl}$ does not accumulate in a single cell (Fig. 5C). Thus localization of Egl and BicD is interdependent: Whenever one protein fails to localize, localization of the other is also affected. Moreover, in $B i c D^{r 26}$ mutant oocytes both mutant BicD protein and the wild-type Egl protein localize to one cell very strongly (Fig. 5C). Thus, the ability of BicD to localize Egl and BicD to the oocyte can be mutated separately from the ability of BicD and Egl to determine the oocyte. Furthermore, this result demonstrates that localization of $\mathrm{Egl}$ in the absence of functional BicD protein is not sufficient for oocyte determination.

\section{Biochemical interaction between $\mathrm{Egl}$ and BicD proteins}

Because Egl and BicD function in the same process, colocalize in the oocyte, and depend on the activity of each other for localization, we tested whether these proteins are part of a protein complex. We used antisera that specifically detect the Egl or BicD proteins in coimmunoprecipitation experiments. Anti-Egl antiserum immunoprecipitates both $\mathrm{Egl}$ and $\mathrm{BicD}$ proteins (Fig. 6A), and anti-BicD antiserum also immunoprecipitates both proteins (Fig. 6B). Anti-Egl fails to immunoprecipitate BicD from extracts that lack Egl protein (from egl ${ }^{W U 5 O} \mathrm{mu}$ tants); also, nonspecific antibodies such as anti- $\gamma$-tubulin (Fig. 6A,B; Zheng et al. 1995), anti-Vasa, or Egl preimmune serum (data not shown) immunoprecipitate neither Egl nor BicD. Thus, the immunoprecipitation reaction shows specificity for $\mathrm{Egl}$ and $\mathrm{BicD}$ and indicates an interaction between the proteins.

To determine whether mutations in either protein affect this interaction, we examined the coimmunoprecipitation of Egl and BicD from extracts of mutant ovaries that contain both $\mathrm{BiCD}$ and $\mathrm{Egl}$ proteins. In $e g 1^{4 e}$ mutants neither BicD nor Egl proteins localize to the oocyte (Fig. 5B,C). In these mutants, BicD and Egl proteins fail to coimmunoprecipitate (Fig. 6C), suggesting that the $e g 1^{4 e}$ mutation may interfere with association of the two proteins. In BicD ${ }^{P A 66}$ mutants, as in egl ${ }^{4 e}$, BicD and Egl proteins do not localize to a single cell (Fig. 5C; Suter and Steward 1991). In BicD ${ }^{P A 66}$ extracts, BicD and Egl proteins coimmunoprecipitate (Fig. 6D), indicating that this mutation may not affect complex formation but rather a common function of the two proteins that is required for localization and function of the protein complex. In BicD ${ }^{r 26}$ mutants, BicD protein localizes more strongly to 1 cell of the 16-cell cyst than in wild type (Wharton and Struhl 1989; Suter and Steward 1991). In this mutant, Egl protein colocalizes with the mutant BicD protein (Fig. 5C) and $\mathrm{Egl}$ and $\mathrm{BicD}$ are coimmunoprecipitated from $B i c D^{r 26}$ ovary extracts (Fig. 6D). This result suggests that $B i c D^{r 26}$ can form a complex with Egl that localizes to 1 cell in the 16-cell cyst, but this complex is unable to promote oocyte differentiation despite having wild-type Egl protein localized to a single cell.

Our data show that BicD and Egl are part of a protein complex. The analysis of $e g l$ and BicD mutant proteins further reveals that complex formation, complex localization to the oocyte, and complex function in oocyte determination are separable functions of the two proteins. 
A

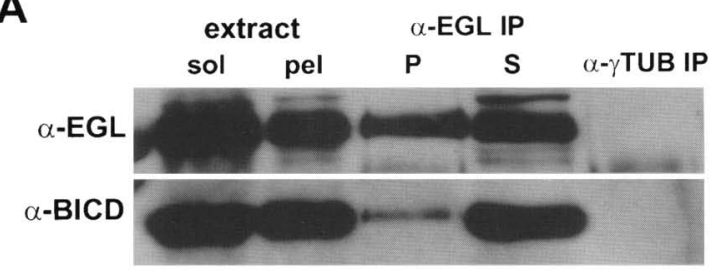

B
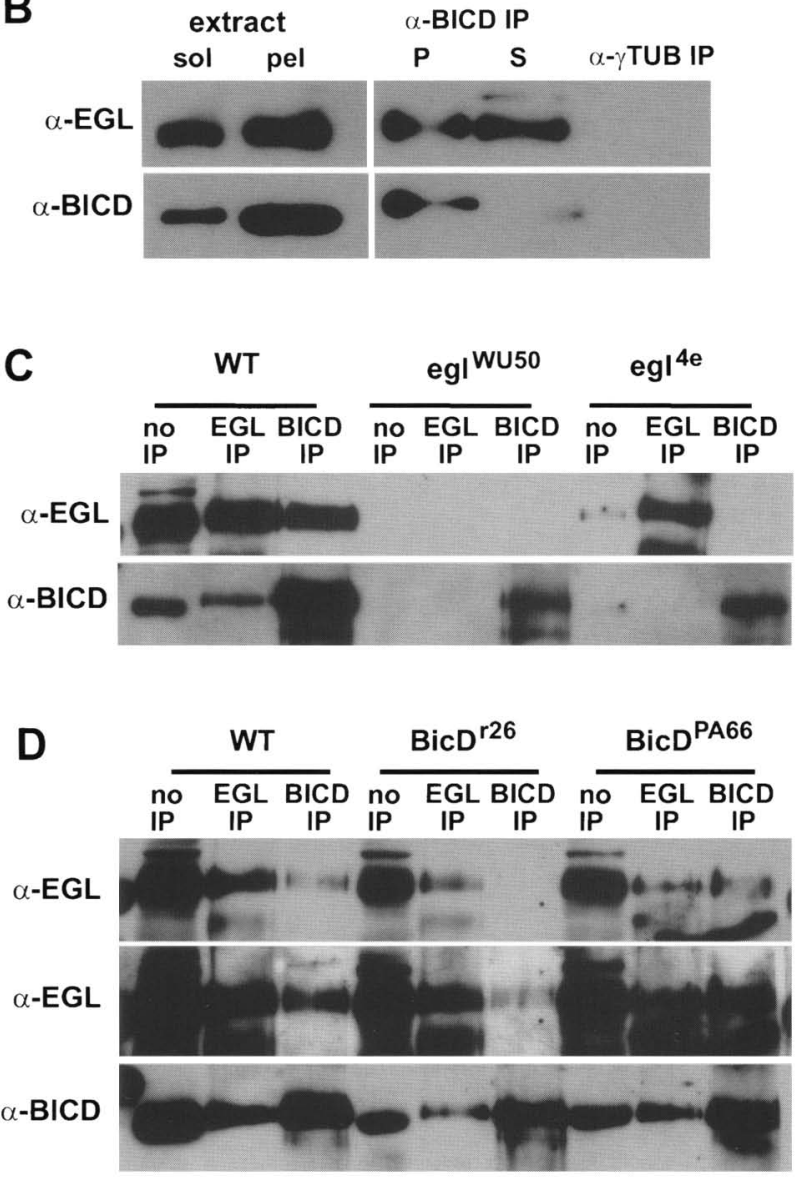

egl and BicD affect osk localization

Genetic interactions suggest that $e g 1$ and BicD not only are required for oocyte determination but also play a role in establishing oocyte polarity. Females carrying a dominant $B i c D$ mutation $\left(B i c D^{D}\right)$ produce embryos that develop with reduced head structures attributable to a partial mislocalization of osk mRNA to the anterior of the oocyte (Ephrussi et al. 1991). In the most extreme case, double-abdomen, or bicaudal, embryos develop, in which ectopic posterior structures replace anterior structures (Mohler and Wieschaus 1986). Antibody staining reveals that compared with wild type, BicD protein accumulation in the early oocyte is more pronounced in $B i c D^{D}$ mutants and that the protein remains at the anterior pole of mutant oocytes during later stages of oo-
Figure 6. Coimmunoprecipitation of $\mathrm{Egl}$ and BicD. In each panel, the antisera used for immunoprecipitation are indicated above the lanes and the antibodies used for Western blotting are indicated to the left. For each immunoprecipitation, homogenized ovaries were spun to produce two fractions, the insoluble (pel) fraction, which was discarded, and the supernatant /sol or no IP), which was used for the immunoprecipitation reaction. $\langle A, B\rangle$ Proteins immunoprecipitated by the reaction are in the lanes labeled $\mathrm{P}$, and the proteins remaining in the supernatant are in the lanes labeled S. $(C, D)$ Supernatants were discarded and only the precipitates were analyzed. (A) Anti-Egl immunoprecipitates both $\mathrm{Egl}$ and $\mathrm{BicD}$ proteins; $(B)$ anti-BicD immunoprecipitates both Egl and BicD proteins. For both experiments, the extract lanes (sol and pel) represent the equivalent of $7 \mu \mathrm{l}$ of ovary extract. The immunoprecipitation lanes each contain the precipitate from $35 \mu \mathrm{l}$ of the soluble fraction of the ovary extract. The $S$ lane contains an equivalent amount of the supernatant from the anti-Egl $(A)$ or anti-BicD $\langle B|$ immunoprecipitation. Note $<50 \%$ of Egl protein is immunoprecipitated by antiEgl antibody $(A)$, whereas the anti-BicD antibody is very efficient $(90 \%)$ in immunoprecipitation of BicD protein $(B)$. We find that anti-BicD antibody is consistently more effective in coimmunoprecipitation of Egl protein $(B)$ than anti-Egl antibody is in coimmunoprecipitation of $\operatorname{BicD}$ protein $(A)$. Although this finding may be attributable to the different effectiveness of the respective antibodies, it may also indicate that $\mathrm{Egl}$ protein is dose-limiting. $(C)$ Immunoprecipitations from egl mutants; $(D)$ immunoprecipitations from BicD mutants. For each egl allele, females were heterozygous for the allele and chromosomal deletion $D f(2 R) b w^{S 46}$; BicD alleles were heterozygous to $D f(2 L)$ TW119. In $C$ the no IP lane contains the equivalent of $2 \mu \mathrm{l}$ of ovary extract and the other lanes contain the immunoprecipitate from $35 \mu \mathrm{l}$ of extract. In extract from egl $1^{W U 50}$ ovaries, BicD protein is visible in a longer exposure in the no IP lane and is clearly present and visible when immunoprecipitated with anti$\mathrm{BicD}$ antiserum. However, no Egl protein is detectable and no BicD protein immunoprecipitates with anti-Egl antiserum. In $D$ the middle panel is a longer exposure of the top anti-Egl Western, to show that Egl does coimmunoprecipitate with anti-BicD from $B i c D^{r 26}$. Also, the no IP lane contains the equivalent of 10 $\mu l$ of ovary extract and the other lanes contain the immunoprecipitate from $35 \mu \mathrm{l}$ of extract.

genesis and early embryogenesis (Wharton and Struhl 19891 .

The amount of egl product in the ovary affects the severity of the dominant $B i c D^{D}$ phenotype dramatically (Mohler and Wieschaus 1986). About one-third of embryos from $B i c D^{D} /+$ females showed some loss of head structures; in contrast, only $1 \%$ of embryos from females that also are heterozygous mutant for egl $\left(B i c D^{D}+/+e g l^{-}\right)$developed abnormally (Table 1). We also found that increasing $e g 1^{+}$copy number in a BicD $D^{D}$ background enhanced the penetrance and severity of the $B i c D^{D}$ phenotype dramatically such that two-thirds of the embryos showed anterior defects, with the frequency of the most severe bicaudal phenotype increasing from $11 \%$ to $43 \%$ (Table 1 ).

To determine whether egl directly affects the extent to which osk RNA mislocalizes in embryos from $B i c D^{D}$ 
Table 1. Genetic interaction between BicD gain-of-function mutations and egl

\begin{tabular}{|c|c|c|c|c|c|}
\hline $\begin{array}{l}\text { Cuticle } \\
\text { phenotype }\end{array}$ & & $\begin{array}{c}\text { Wild type } \\
(\%)\end{array}$ & $\begin{array}{c}B i c D^{D} / \operatorname{eg} I^{-} \\
(\%)\end{array}$ & $\begin{array}{c}B i c D^{D} /+ \\
(\%)\end{array}$ & $\begin{array}{c}\mathrm{BicD}^{D} ; 4 \times e g 1^{+} \\
(\%)\end{array}$ \\
\hline Normal & exumit & 97 & 94 & 64 & 20 \\
\hline Headless & Humiti & 1 & 1 & 17 & 20 \\
\hline Asymmetric & Cument & 0 & 0 & 5 & 11 \\
\hline $\begin{array}{c}\text { Symmetric } \\
\text { bicaudal }\end{array}$ & 4.69 & 1 & 0 & 11 & 43 \\
\hline $\begin{array}{l}\text { osk RNA } \\
\text { localization }\end{array}$ & & $\begin{array}{c}\text { Wild type } \\
(\%)\end{array}$ & $\begin{array}{c}B i c D^{D} / e g I^{-} \\
|\%|\end{array}$ & $\begin{array}{c}B i c D^{D} /+ \\
(\%)\end{array}$ & $\begin{array}{c}B i c D^{D} ; 4 \times e g 1^{+} \\
\{\%\}\end{array}$ \\
\hline Normal & & 100 & 86 & 51 & 43 \\
\hline Weak anterior & & 0 & 14 & 29 & 37 \\
\hline Strong anterior & & 0 & 0 & 12 & 15 \\
\hline
\end{tabular}

The allele $B i C D^{71.34}$ was used for $B i c D^{D} ; e g l^{W U 50}$ was used for $e g I^{-} .4 \times e g I^{+}$flies contain the two endogenous copies of the $e g 1$ gene and two additional copies of an $e g l^{+}$transgene. Of at least 150 eggs that were examined, all embryos that hatched were assigned to the "normal" class for cuticle phenotype. At least 25 cuticles were examined for each class, with more being examined for those classes that produced very few hatching embryos. For osk in situ hybridizations, at least 35 embryos were counted. Because of the variability of the in situ hybridization technique, we assume that embryos with weak or strong anterior localization of osk RNA can develop larval cuticles with a bicaudal phenotype. Eggs that did not develop a cuticle or did not stain by in situ hybridization were counted but not included here.

females, we examined the distribution of osk RNA by in situ hybridization on embryos from different genetic backgrounds. We found that in a BicD $D^{D}$ mutant background reducing the amount of egl wild-type product decreased ectopic localization of osk to the anterior and increasing the amount of egl wild-type product enhanced the mislocalization of osk to the anterior (Table 1). Because the effect of $B i c D^{D}$ mutants depends on $e g l$ wildtype function, we conclude that $e g l$ and $B i c D$ act in the same pathway and that $e g l$ and $B i c D$ function in concert to control osk RNA localization.

\section{Egl affects dorsoventral polarity}

The pattern of Egl protein distribution in later stages of oogenesis as well as the effect of egl on osk RNA localization suggest that egl may not only play a role in oocyte determination but may also be involved in later aspects of RNA localization. This question cannot be addressed with the existing egl alleles, because these mutations completely block oocyte development. However, several of our egl $^{+}$transgenes are not expressed well and thus only partially complement the egl phenotype.

We find that eggs produced from $\left.\mathrm{egl}^{-} ; \mathrm{P}_{\mathrm{egl}} \mathrm{H}^{+}\right]$females display various degrees of egg shell ventralization, such as fusion of the two dorsal appendages and complete loss of dorsal appendages (Fig. 7). This phenotype resembles that of eggs produced by females mutant for gurken (grk), the dorsalizing signal (Neuman-Silberberg and Schüpbach 1994). To test whether this effect on egg shell morphology was indeed caused by improper localization of grk RNA, grk RNA distribution was assayed in eg1-; $P\left[e g I^{+}\right]$ovaries. We found that grk RNA levels are re-

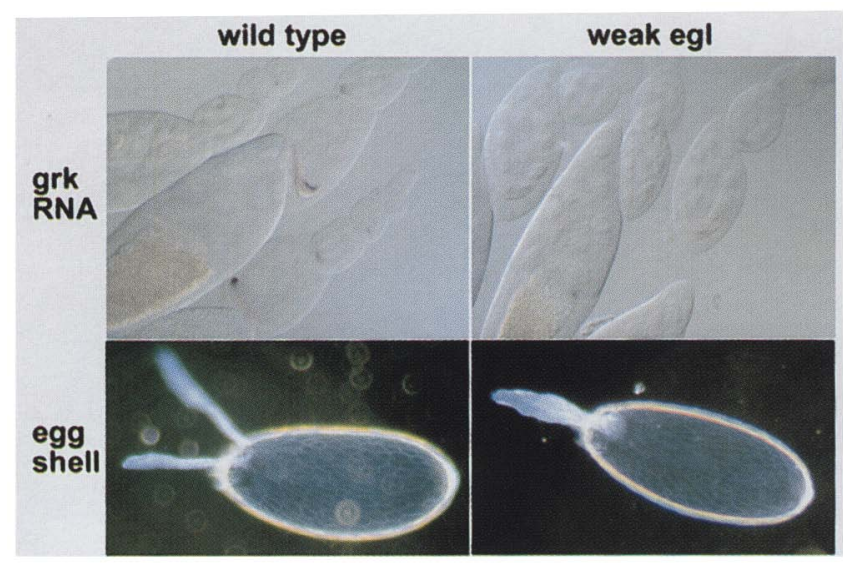

Figure 7. egl affects grk RNA localization. Reduced $e g l$ activity reveals a role of $e g l$ in dorsoventral polarity of the egg. In wildtype ovaries (left), grk RNA initially accumulates in the oocyte, and by stage 9 of oogenesis grk RNA localizes to the anterior margin of the oocyte in close association with the oocyte nucleus. In ovaries that have reduced egl function $\{r i g h t\}, g r k$ RNA is either only weakly localized or unlocalized. Presumably as a consequence of partial loss of grk function, eggshells produced by such females shows a loss of dorsal fates resulting in fused dorsal appendages $(77 \%)$ or complete loss of dorsal appendages $(18 \%)$. The weak egl genotype used is y $\mathrm{w}$; egl $\mathrm{l}^{\text {WU5O }}$ with one copy of an $e g 1^{+}$transgene (CA3B or CA13F) that complements the egl phenotype only partially. grk in situ hybridizations were hybridized as in Ephrussi et al. (1991). 
duced in these ovaries (Fig. 7). The distribution of osk RNA was unaffected in these oocytes (data not shown). Also, the oocyte nucleus localized to the dorsal anterior side of the oocyte, even in the absence of grk localization (Fig. 7A). Because both of these processes require an intact microtubule cytoskeleton (Koch and Spitzer 1983; Pokrywka and Stephenson 1994), grk localization in this genotype may be perturbed by a failure of RNA localization, rather than by destabilization of microtubule structure. The microtubule structure of these oocytes is intact (data not shown). Our results suggest that Egl and BicD act in RNA localization in both early and later stages of oogenesis.

\section{Discussion}

We have identified a protein complex that contains Egl and $\mathrm{BicD}$ proteins and is essential for the designation of 1 of 16 sister cells as the oocyte. In the absence of either egl or BicD function, no oocyte develops and all 16 cells become polyploid nurse cells. The existence of a complex containing these proteins is suggested strongly by the genetic interaction between the loci and by the colocalization of the protein products. Concomitant with the first morphological signs of oocyte differentiation, that is, the formation of synaptonemal complex in the pro-oocyte (Carpenter 1975), both Egl and BicD become enriched in a single cell. Mutations in either egl or BicD affect the oocyte localization pattern of the other, suggesting that complex formation precedes or coincides with localization of the complex to a single cell and subsequent determination of the oocyte. Complex formation, complex localization, and complex function can be affected separately by $e g l$ or $B i c D$ mutations, providing evidence for the existence of distinct functional domains in the two proteins.

\section{egl and $\mathrm{BicD}$ in oocyte determination}

Egl is localized to a single cell and is required for the development of that cell as the oocyte; however, three observations indicate that egl is not the oocyte determinant. First, increasing the copy number of egl+ increases the levels of $\mathrm{Egl}$ protein within the germarium but does not cause multiple cells within the cluster to obtain oocyte fate (J. Mach and R. Lehmann, unpubl.). Second, in egl null mutations all 16 cells initially follow the prooocyte fate and form synaptonemal complex before reverting to the nurse cell fate (Carpenter 1994). Third, in $B i c D^{r 26}$ mutants, Egl protein is highly enriched in a single cell but this cell does not follow the oocyte fate. Thus Egl protein alone is not sufficient to control oocyte fate. We therefore favor the idea that Egl and BicD determine oocyte fate as a protein complex by controlling the distribution of molecules that regulate oocyte and nurse cell differentiation.

An early sign of oocyte determination is the formation of the synaptonemal complex. However, germ cells with three or four ring canals located adjacent to the oocyte form synaptonemal complexes transiently but eventu- ally follow the nurse cell fate (Carpenter 1975). This transient expression of one aspect of oocyte fate may reflect the distribution of an oocyte determinant. At this stage of oogenesis, in germarial regions $2 \mathrm{~A}$ and $2 \mathrm{~B}, \mathrm{Egl}$ and $\mathrm{BicD}$ proteins become enriched in the future oocyte. If $\mathrm{Egl}$ and $\mathrm{BicD}$ are involved in localizing oocyte determining factors, lower amounts of these factors in cells adjacent to the oocyte may account for this transient entry into meiosis. Consistent with this hypothesis, in eg1 mutants all 16 cells form synaptonemal complexes transiently (Carpenter 1994). According to this model, egl may be required not for the activation or synthesis of oocyte-determining factors, but rather for producing a critical concentration of these factors in the future oocyte.

Differentiation of the nurse cell-oocyte cluster requires the establishment of two cell fates: the premeiotic oocyte and polyploid nurse cells. In $e g 1$ and $B i c D$ mutant ovaries the cell that would normally become an oocyte develops as a sixteenth nurse cell; thus, the same factors that promote oocyte determination may also repress nurse cell fate. Common to both oocyte and nurse cell fate decisions is a change from normal cell cycle regulation: The oocyte arrests in meiotic prophase and the nurse cells become polyploid by DNA replication without cytokinesis (Spradling 1993). A cyclinE mutation perturbs this decision, causing one of the cells that would normally become a nurse cell to develop as a second oocyte (Lilly and Spradling 1996); thus, determination of oocyte and nurse cell fate may be linked to the differential distribution or activation of cell cycle regulators. It is therefore intriguing to speculate that the EglBicD complex is involved in the distribution of these regulators.

\section{egl and $\mathrm{BicD}$ in axis determination}

Specification of the oocyte as different from its 15 sister cells and positioning of the oocyte posterior to the nurse cells are essential for the subsequent polarization of the oocyte. Oocyte determination requires egl and BicD; oocyte positioning requires the function of a number of genes such as dicephalic, homeless, and spindleC (Frey et al. 1984; González-Reyes and St Johnston 1994; Gillespie and Berg 1995|. Oocyte determination both requires and stabilizes a polarized microtubule network that leads to microtubule-mediated transport of RNA from the nurse cells into the future oocyte (Theurkauf et al. 1993). Among these RNAs are grk, osk, and bicoid, which encode essential regulators of the two embryonic axes (Pokrywka and Stephenson 1991, 1994). The anterior-posterior axis is thought to be set when Grk protein, a transformation growth factor- $\alpha$ (TGF- $\alpha$ )-like molecule, is secreted from the oocyte and signals to the underlying follicle cells to promote posterior follicle cell fate (Roth and Schüpbach 1994; González-Reyes et al. 1995; for review, see Lehmann 1995; Ray and Schüpbach 1996). A yet unknown signal returned from the follicle cells leads to the repolarization of the microtubule network in the oocyte such that the MTOC at the posterior cortex is 
lost and microtubules now extend with the minus end from the anterior toward the posterior. This repolarization has two consequences. First, microtubule polarity leads to the sorting of RNA molecules along the anterior-posterior axis, that is, bicoid RNA becomes localized to the anterior pole and osk RNA becomes localized to the posterior pole of the oocyte. Second, grk RNA moves in close association with the oocyte nucleus to the dorsal anterior margin of the oocyte. In another intercellular signaling step, Grk protein, secreted from the oocyte, now promotes dorsal follicle cell fate.

Each step-first determination of oocyte fate, then specification of the anterior-posterior axis, and finally specification of the dorsoventral axis-requires both RNA transport along a polarized microtubule network and the function of the Egl-BicD complex. The distribution of $\mathrm{Egl}$ and $\mathrm{BiCD}$ proteins resembles that of the minusends of microtubules, and mutations in either egl or $B i c D$ disrupt microtubule stability or the initiation of the microtubule organizing center in the oocyte. Consequently, many RNAs that are transported into the oocyte during early oogenesis do not accumulate in a single cell in $e g l$ and BicD mutants.

The role of the Egl-BicD complex in anterior-posterior axis formation is suggested by its effect on localization of osk RNA. egl and BicD mutants abolish transport of osk into the oocyte. In $B i c D^{D}$ mutants, the $B i c D^{D}-\mathrm{Egl} \mathrm{com}$ plex directs ectopic localization of osk RNA to the anterior of the oocyte (Ephrussi et al. 1991). The osk localization signal in the osk $3^{\prime}$-untranslated region (UTR) contains separable regions for oocyte and posterior localization of osk (Kim-Ha et al. 1993). Because the Egl-BicD complex affects the initial localization of osk to the oocyte we favor the model that the complex mediates ectopic localization via the oocyte localization signal. Our model would predict that during normal oogenesis, osk RNA is released from the BicD-Egl complex once the complex relocates to the anterior pole. As a consequence, osk RNA localization at the anterior is only transient and osk RNA becomes anchored stably at the posterior pole through sequences in the osk 3' UTR necessary for posterior localization. In $B i c D^{D}$ mutants, however, the $\mathrm{BicD}^{\mathrm{D}}-\mathrm{Egl}$ protein complex is somehow altered such that it is unable to release osk RNA after the complex has moved to the anterior and thus osk RNA remains at the anterior. One prediction of this hypothesis is that anterior localization of osk RNA in $B i c D^{D} \mathrm{mu}$ tants depends on the oocyte localization domain and not the posterior localization domain within the osk $3^{\prime}$ UTR. This hypothesis would explain why in $B i c D^{D}$ mutants osk is localized to the anterior pole independent of gene functions such as staufen, cappuccino, and spire, which are required for the normal posterior localization of osk (Manseau and Schüpbach 1989; Ephrussi et al. 1991; Lehmann and Nüsslein-Volhard 1991).

The Egl-BicD complex is also involved in establishment of the dorso-ventral axis. We show that egl affects eggshell morphology and that this phenotype can be attributed to a defect in grk RNA localization. Similarly, Mohler and Wieschaus (1986) observed that $90 \%$ of egg- shells produced by $B i c D^{D}$ mutant females have fused dorsal appendages, indicating ventralization as a result of reduced function of the grk pathway. Thus the Egl-BicD complex may not only affect initial transport of grk RNA into the oocyte where Grk sets the anterior-posterior axis but may also affect grk RNA localization to the anterior during mid-oogenesis when Grk sets the dorsoventral axis.

Although it is possible that the Egl-BicD complex affects RNA localization solely by stabilizing microtubule structure, we favor the hypothesis that association of the Egl-BicD complex with microtubules stabilizes microtubules and that the complex then acts as a link between microtubules and the RNA localization machinery. If egl and BicD act directly to localize RNAs, these proteins may either bind RNA or associate with an RNA-binding protein, such as Orb, which has a distribution strikingly similar to that of Egl and BicD and a localization that depends on Egl and BicD function (Lantz et al. 1994; Christerson et al. 1994).

\section{Materials and methods}

Fly strains

$e g 1^{\text {WU5O }}, e g 1^{R C 12}, e g 1^{P B 23}, e g l^{P R 29}, e g 1^{P V 27}$, and BicD ${ }^{P A 66}$ are described in Schüpbach and Wieschaus (1991). egl ${ }^{2 b}, e g l^{2 e}, e g l^{3 e}$, and $e g 1^{4 e}$ were isolated by A. Ephrussi and F. Pelegri (Pelegri $1994)$ as dominant suppressors of $B i c D^{D}$. eg1 $1^{1287}$ and eg1 $1^{6267}$ were isolated by the late L. Kalfayan (University of North Carolina, Chapel Hill). BicD ${ }^{26}$ and the $B i c D^{D}$ allele, $B i C D^{7134}$, are described in Mohler and Wieschaus \{1986). All other strains are as described in Lindsley and Zimm (1992).

egl chimeras by pole cell transplantation

To generate chimeric flies with wild-type germ cells in an $e g l$ mutant soma, pole cells from scarlet (st) ebony (e) donors were transplanted into recipients from the cross egl $I^{\text {WUSO/ }}$ $\mathrm{CyO} \times e g^{R C 12} / \mathrm{CyO}$. Chimeric animals were evaluated for fertility and the ability to produce st $e$ progeny from the introduced germ cells. In the reverse experiment, pole cells from the cross BG07 egl ${ }^{\text {WU5O }} / \mathrm{CyO}$ females $\times$ egl ${ }^{\text {WU5O }}$ homozygous males were transplanted into recipients from the cross Oregon- $R$ females $\times O v O^{D} / Y$ males. $B G 07$ is a nuclear lacZ enhancer trap expressed in the germ cells and was a kind gift from F. Laski (University of California, Los Angeles). Chimeric flies were analyzed for the presence of introduced germ cells by staining the ovaries for $\beta$-galactosidase activity. Only egl homozygous germ cells will stain for $\beta$-galactosidase.

\section{Cloning and sequence analysis of $\mathrm{egl}$}

By cytology, egl maps to polytene bands 59F5-8 and is uncovered by several chromosomal deletions. Two chromosomal deletions (Reed 1992) complement egI mutations: $D f(2 R) b w^{D R}$ defines the centromere-proximal limit of the egl region and $D f(2 R)$ or ${ }^{B R-11}$ defines the centromere-distal limit of the egl region. To provide entry into the region, a junction clone, containing sequences from the egl region fused to sequences from the distal end of the deletion, was isolated from a $D f(2 R) o r^{B R-11} /+$ genomic library using a distal probe provided by L. Hall (State University of New York, Buffalo). The region was isolated as a series of overlapping cosmids (library courtesy of J. 
Tamkun, University of California, Santa Cruz; Tamkun et al. 1992) covering the 80 -kb region between the deletion breakpoints. The position within the walk was monitored by hybridizing each cosmid to quantitative DNA blots prepared from wild-type and deletion-heterozygous DNA as well as by in situ hybridization to salivary gland chromosome squashes from wild-type and deletion-heterozygous larvae.

cDNAs corresponding to the egl transcript were isolated from a cDNA library from 4- to 8-hr embryos (library courtesy of N. Brown, Wellcome/CRC Institute, Cambridge, UK; Brown and Kafatos 1988). The longest cDNA was sequenced by sonication and sequencing of random clones (Bankier et al. 1987). The sequences were assembled into contigs using the DNASTAR SeqMan program. Conceptual translation of the longest ORF from the start codon with the best match to the Drosophila initiation sequence [CAAC instead of AGCA, GTCC, or CGAG, for the three ATGs upstream (Cavener 1987)] predicts a $98-\mathrm{kD}$ protein. The predicted 772-base $5^{\prime}$ UTR contains stop codons on all three reading frames, indicating that the beginning of the ORF is contained within the sequenced cDNA.

To compare the $e g 1$ sequence with sequences identified previously, BLAST (Atschul et al. 1990) algorithms were used through the Baylor College of Medicine Search Launcher (http://dot.imgen. bcm.tmc.edu:9331/seq-search/protein-search.html). To sequence the egl alleles, PCR products spanning the coding sequence were generated, purified with Centricon 100 columns, and sequenced by the Whitehead Sequencing Facility.

To express the egl gene under the control of the ovarian tumorgene (otu) promoter, the pCOG construct (kind gift of D. Robinson and L. Cooley, Yale University School of Medicine, New Haven, CT) was used. This construct has the otu promoter upstream of a polylinker and the K10 3' UTR, all in the transformation vector $\mathrm{pCaSpeR} 2$. A fragment of the $e g 1 \mathrm{cDNA}$ from the EcoRV site 70 nucleotides upstream of the start of translation to the NotI site in the NB40 vector was ligated into the HpaI and NotI sites of pCOG.

\section{Sequence of egl alleles}

$e g l^{P B 23}$, whose alteration in transcript size initially identified the egl transcript, has a splice donor site mutation. Sequencing of RT-PCR products from egl ${ }^{p B 23}$ mRNA confirms that the third intron is not excised, adding 200 bases to the egl transcript. Translation of this message should produce 126 amino acids of Egl, followed by 22 intron-encoded amino acids before reaching a stop codon in the intron. In $e g l^{W U 50}$ the splice acceptor site of the fourth intron is mutated, causing a frameshift after residue 777 . eg $7^{\text {WU5O }}$ also has an amino-acid substitution at residue $399 . e g 1^{P R 29}$ has a stop codon after amino acid 279 . From sequence analysis we would predict that egl $1^{P B 23}, e g 1^{W U 50}$, and egl $I^{P R 29}$ mutants produce truncated proteins that on a protein blot should be detected at a smaller size than the wild-type protein. Although the Egl antigen used for immunization included the protein regions expected to be present in the mutants, no Egl protein was detected in these mutants either by Western blot or by whole-mount immunofluorescence. We cannot exclude the possibility that the $\alpha$-Egl antibody does not recognize the protein sequences remaining in the three mutants, but we favor the hypothesis that the protein truncations lead to protein instability.

\section{Generation of antibodies and Western blotting}

To generate antibodies, a fragment of the $e g l$ coding sequence, from a BamHI site generated by PCR just after the ATG at the start of translation to the $M s c I$ site at amino acid 415 , was fused in-frame to PET3a (Rosenberg et al. 1987). This construct was expressed in bacterial strain BL21(DE3) PlysS. The antigen was purified as inclusion bodies, gel-purified, and sent as a gel slice to HRP, Inc. (Denver, PA) for production of rabbit sera. Serum from the third bleed was used for all analyses.

For Western blotting, all gels were $8 \%$ acrylamide, blotted semidry onto polyvinylidene difluoride (PVDF) membrane (Millipore) using the Hoefer Semi-Phor. Anti-Egl serum was used at 1:5000, anti-Vas at 1:50,000, and anti-BicD at 1:2000 in Superblock blocking agent (Pierce) with $0.05 \%$ Tween 20, as described in the manufacturer's instructions. HRP-conjugated secondary (anti-rabbit from Amersham or anti-mouse from Jackson Labs/ was developed with chemiluminescent detection reagents (Pierce) as described in the manufacturer's instructions.

\section{Ovary in situ hybridization}

RNA in situ hybridization on ovaries and embryos were performed either as described by Ephrussi et al. (1991) or by Suter and Steward (1991). DNA probes were labeled using the digoxigenin DNA labeling and detection kit from Boehringer Mannheim.

For other stainings, ovaries were dissected in PBS, fixed for 10 min in $8 \%$ EM grade formaldehyde (Ted Pella), and extracted for $1-2 \mathrm{hr}$ in $1 \%$ Triton X-100 in PBS. The ovaries were labeled with BODIPY 581/591 phalloidin (Molecular Probes), as described for embryos in Wieschaus and Nüsslein-Volhard (1986), and then incubated in 1:5000 OliGreen (Molecular Probes), $5 \mu \mathrm{g} / \mathrm{ml}$ of RNase $A$ and $0.1 \%$ Triton X-100 in PBS for $30 \mathrm{~min}$, rinsed in PBS, and mounted in $90 \%$ glycerol, $1 \times$ PBS, $1 \mathrm{mg} / \mathrm{ml}$ of phenylenediamine.

For antibody staining, the ovaries were fixed and extracted as above, then blocked in $1 \times$ PBS, $1 \%$ BSA, $0.1 \%$ Triton $\mathrm{X}-100$, and $2 \%$ normal donkey serum. The ovaries were then incubated overnight in the same solution containing primary antibody, anti-Egl at 1:1000, anti-BicD monoclonal 1B11 (kind gift from B. Suter, McGill University, Montreal, Canada) at 1:500 or FITC anti- $\alpha$-tubulin from $\mathrm{T}$. Orr-Weaver at 1:250. Cy3 donkey antirabbit or FITC donkey anti-mouse IgG secondary antibodies were used at 1:500. The ovaries were then stained with OliGreen and mounted as above. For the inhibitor studies, flies were fed colchicine for $18 \mathrm{hr}$ as described in Theurkauf et al. (1993).

All immunofluorescence images were made with the Bio-Rad MRC 600 Confocal and processed with Adobe Photoshop 3.0. All composites were made with Aldus Freehand 5.0.

\section{Immunoprecipitations}

To prepare ovary extract, ovaries were dissected in cold $1 \times$ PBS. For each $50 \mu \mathrm{l}$ of ovaries, $180 \mu \mathrm{l}$ of buffer without detergent, but with protease inhibitors (final with detergent: $50 \mathrm{~mm}$ Tris at $\mathrm{pH}$ $8.0 ; 150 \mathrm{~mm} \mathrm{NaCl} ; 10 \mu \mathrm{g} / \mathrm{ml}$ each of leupeptin, Pefabloc, and pepstatin from Boehringer Mannheim; $1 \%$ aprotinin and $0.1 \mathrm{~mm}$ PMSF from Sigmal were added. The extract was homogenized and spun at maximum speed in a microcentrifuge at $4^{\circ} \mathrm{C}$ for 5 min. The resulting pellet was discarded as the insoluble fraction. Ten percent NP-40 was added to the supernatant to a final concentration of $1 \%$.

For each immunoprecipitation reaction, $75 \mu \mathrm{l}$ of the soluble fraction of the extract was combined with $2 \mu$ l of antibody (rat anti-BicD, a kind gift from $\mathrm{R}$. Wharton, Duke University Medical Center, Durham, NC) and incubated on ice for $1 \mathrm{hr}$. Thirty microliters of a 1:1 suspension of protein A-Sepharose (Pharmacia) was added and incubated on ice for $1 \mathrm{hr}$ with occasional mixing. The beads were rinsed once with cold NP-40 buffer 
with protease inhibitors, and washed three times for 5 min each. The beads were resuspended in $50 \mu \mathrm{l}$ of sample buffer $(125 \mathrm{~mm}$ Tris at pH 6.8, 4\% SDS, $20 \%$ glycerol, $5 \mathrm{~m}$ urea, $0.01 \%$ bromphenol blue) plus $10 \mu \mathrm{l}$ of $1 \mathrm{~m}$ DTT and boiled for $5 \mathrm{~min}$ before being loaded on a gel.

\section{Acknowledgments}

We thank Terry Orr-Weaver, Beat Suter, Robin Wharton, and Yixian Zheng for antibodies; Doug Robinson, Lynn Cooley, Linda Hall, John Tamkun, and Nick Brown for DNA and plasmids; and Bruce Reed, Frank Laski, Kristi Wharton, and the late Laura Kalfayan for fly stocks. We thank Liuda Ziaugra at the Whitehead sequencing facility for sequencing egl alleles. We thank Adelaide Carpenter for discussion and advice. We would like to thank Angelika Amon, Sharon Bickel, Zandy Forbes, Chris Rongo, Mark Van Doren, and Phil Zamore for discussion and critical reading of the manuscript. J.M. was supported by a predoctoral fellowship from the National Science Foundation and a National Institutes of Health training grant. This project was supported by a fellowship from the Packard Foundation to R.L.

The $e g l$ sequence has been deposited in the Genbank database under accession number U86404.

The publication costs of this article were defrayed in part by payment of page charges. This article must therefore be hereby marked "advertisement" in accordance with 18 USC section 1734 solely to indicate this fact.

\section{References}

Atschul, S.F., W. Gish, W. Miller, E.W. Myers, and D.J. Lipman. 1990. Basic local alignment search tool. I. Mol. Biol. 215: 403-410.

Bankier, A.T., K.M. Weston, and B.G. Barrell. 1987. Random cloning and sequencing by the M13/dideoxynucleotide chain termination method. Methods Enzymol. 155: 51 .

Berger, B., D.B. Wilson, E. Wolf, T. Tonchev, M. Milla, and P.S. Kim. 1995. Predicting coiled coils by use of pairwise residue correlations. Proc. Natl. Acad. Sci. 92: 8259-8263.

Brown, N.H. and F.C. Kafatos. 1988. Functional cDNA libraries from Drosophila embryos. J. Mol. Biol. 203: 425-437.

Carpenter, A.T.C. 1975. Electron microscopy of meiosis in Drosophila melanogaster females. II: The recombination nodule-A recombination-associated structure at pachytene? Proc. Natl. Acad. Sci. 72: 3186-3189.

- 1994. egalitarian and the choice of cell fates in Drosophila melanogaster oogenesis. Ciba Found. Symp. 182: 223-254.

Cavener, D.R. 1987. Comparison of the consensus sequence flanking translational start sites in Drosophila and vertebrates. Nucleic Acids Res. 15: 1353-1361.

Cheung, H.-K., T. Serano, and R.S. Cohen. 1992. Evidence for a highly selective RNA transport system and its role in establishing the dorsoventral axis of the Drosophila egg. Development 114: 653-661.

Christerson, L.B. and D.M. McKearin. 1994. orb is required for anteroposterior and dorsoventral patterming during Drosophila oognenesis. Genes \& Dev. 8: 614-628.

Clark, K.A. and D.M. McKearin. 1996. The Drosophila stonewall gene encodes a putative transcription factor essential for germ cell development. Development 122: 937-949.

Ephrussi, A., L.K. Dickinson, and R. Lehmann. 1991. Oskar organizes the germ plasm and directs localization of the posterior determinant nanos. Cell 66: 37-50.
Frey, A., K. Sander, and H. Gutzeit. 1984. The spatial arrangement of germ line cells in ovarian follicles of the mutant dicephalic in Drosophila melanogaster. Wilhelm Roux's Arch. Dev. Biol. 193: 288-393.

Gillespie, D.E. and C.A. Berg. 1995. homeless is required for RNA localization in Drosophila oogenesis and encodes a new member of the DE-H family of RNA-dependent ATPases. Genes \& Dev. 9: 2495-2508.

González-Reyes, A. and D. St Johnston. 1994. Role of oocyte position in establishment of anterior-posterior polarity in Drosophila. Science 266: 639-642.

González-Reyes, A., H. Elliott, and D. St Johnston. 1995. Polarization of both major body axes in Drosophila by gurkentorpedo signaling. Nature 375: 654-658.

Kim-Ha, J., J.L. Smith, and P.M. Macdonald. 1991. oskar mRNA is localized to the posterior pole of the Drosophila oocyte. Cell 66: 23-35.

Kim-Ha, J., P.J. Webster, J.L. Smith, and P.M. Macdonald. 1993. Multiple RNA regulatory elements mediate distinct steps in localization of oskar mRNA. Development 119: 169-178.

King, R.C. 1970. Ovarian development in Drosophila melanogaster. Academic Press, New York, NY.

Koch, E.A. and R.H. Spitzer. 1983. Multiple effects of colchicine on oogenesis in Drosophila: Induced sterility and switch of potential oocyte to nurse-cell developmental pathway. Cell Tissue Res. 228: 21-32.

Lantz, V., L. Ambrosio, and P. Schedl. 1992. The Drosophila orb gene is predicted to encode a sex-specific germline RNAbinding protein and has localized transcripts in ovaries and early embryos. Development 115: 75-88.

Lantz, V., J.S. Chang, J.I. Horabin, D. Bopp, and P. Schedl. 1994. The Drosophila orb RNA-binding protein is required for the formation of the egg chamber and establishment of polarity. Genes \& Dev. 8: 598-613.

Lehmann, R. 1995. Establishment of embryonic polarity during Drosophila oogenesis. Semin. Dev. Biol. 6: 25-38.

Lehmann, R. and C. Nüsslein-Volhard. 1991. The maternal gene nanos has a central role in posterior pattern formation of the Drosophila embryo. Development 112: 679-691.

Lilly, M.A. and A.C. Spradling. 1996. The Drosophila endocycle is controlled by CyclinE and lacks a checkpoint ensuring S-phase completion. Genes \& Dev. 10: 2514-2526.

Lin, H. and A.C. Spradling. 1995. Fusome asymmetry and oocyte determination in Drosophila. Dev. Genet. 16: 6-12.

Lin, H., L. Yue, and A.C. Spradling. 1994. The Drosophila fusome, a germline-specific organelle, contains membrane skeletal proteins and functions in cyst formation. Development 120: 947-956.

Lindsley, D.L. and G.G. Zimm. 1992. The genome of Drosophila melanogaster. Academic Press, San Diego, CA.

Manseau, L.J. and T. Schüpbach. 1989. cappuccino and spire: Two unique maternal-effect loci required for both the anteroposterior and dorsoventral patterns of the Drosophila embryo. Genes \& Dev. 3: 1437-1452.

Mohler, J. and E.F. Wieschaus. 1986. Dominant maternal effect mutations of Drosophila melanogaster causing the production of double-abdomen embryos. Genetics 112: 808-822.

Neuman-Silberberg, F.S. and T. Schüpbach. 1994. Dorsoventral axis formation in Drosophila depends on the correct dosage of the gene gurken. Development 120: 2457-2463.

Pelegri, F. 1994. "Chromatin regulators and the determination of embryonic polarity in Drosophila." Ph.D. thesis. Massachusetts Institute of Technology, Cambridge, MA.

Pokrywka, N.J. and E.C. Stephenson. 1991. Microtubules mediate the localization of bicoid RNA during Drosophila oogenesis. Development 113: 55-66. 
1994. Localized RNAs are enriched in cytoskeletal extracts of Drosophila oocytes. Dev. Biol. 166: 210-219.

Ran, B., R. Bopp, and B. Suter. 1994. Null alleles reveal novel requirements for Bic-D during Drosophila oogenesis and zygotic development. Development 120: 1233-1242.

Ray, R. and T. Schüpbach. 1996. Intercellular signalling and the polarization of body axes during Drosophila oogenesis. Genes \& Dev. 10: 1711-1723.

Reed, B.H. 1992. "The genetic analysis of endoreplication in Drosophila melanogaster. Ph.D. thesis. Pembroke College, University of Cambridge, Cambridge, MA.

Rosenberg, A.H., B.N. Lade, D. Chui, W. Lin, J.J. Dunn, and F.W. Studier. 1987. Vectors for selective expression of cloned DNAs by T7 RNA polymerase. Gene 56: 125-135.

Roth, S. and T. Schüpbach. 1994. The relationship between ovarian and embryonic dorsoventral patterning in Drosophila. Development 120: 2245-2257.

Schüpbach, T. and E. Wieschaus. 1991. Female sterile mutations on the second chromosome of Drosophila melanogaster. II. Mutations blocking oogenesis or altering egg morphology. Genetics 129: 1119-1136.

Spradling, A.C. 1986. P element-mediated transformation. In Drosophila: A practical approach (ed. D.B. Roberts), pp. 175197. IRL Press, Oxford, UK.

. 1993. Developmental genetics of oogenesis. In The development of Drosophila melanogaster (ed. M. Bate and A. Martinez Arias), pp. 1-70. Cold Spring Harbor Laboratory Press, Cold Spring Harbor, NY.

St Johnston, D. and C. Nüsslein-Volhard. 1992. The origin of pattern and polarity in the Drosophila embryo. Cell 68: 201219.

Suter, B. and R. Steward. 1991. Requirement for phosphorylation and localization of the Bicaudal-D protein in Drosophila oocyte differentiation. Cell 67: 917-926.

Suter, B., L.M. Romberg, and R. Steward. 1989. Bicaudal-D, a Drosophila gene involved in developmental asymmetry: Localized transcript accumulation in ovaries and sequence similarity to myosin heavy chain tail domains. Genes \& Dev. 3: $1957-1968$.

Tamkun, J.W., R. Deuring, M.P. Scott, M. Kissinger, A.M. Pattattucci, T.C. Kaufman, and J.A. Kennison. 1992. brahma: A regulator of Drosophila homeotic genes structurally related to the yeast transcriptional activator SNF2/SW12. Cell 68: $561-572$.

Theurkauf, W.E., S. Smiley, W.L. Wong, and B.M. Alberts. 1992. Reorganization of the cytoskeleton during Drosophila oogenesis: Implications for axis specification and intercellular transport. Development 115: 923-936.

Theurkauf, W.E., B.M. Alberts, Y.N. Jan, and T.A. Jongens. 1993. A central role for microtubules in the differentiation of Drosophila oocytes. Development 118: 1169-1180.

Wharton, R.P. and G. Struhl. 1989. Structure of the Drosophila BicaudalD protein and its role in localizing the posterior determinant nanos. Cell 59: 881-892.

Wieschaus, E.F. and C. Nüsslein-Volhard. 1986. Looking at embryos. In Drosophila: A practical approach (ed. D.B. Roberts), pp. 199-227. IRL Press, Oxford, UK.

Wilson, R., R. Ainscough, K. Anderson, C. Baynes, M. Berks, J. Bonfield, J. Burton, M. Connell, T. Copsey, J. Cooper, et al. 1994. 2.2 $\mathrm{Mb}$ of contiguous nucleotide sequence from chromosome III of C. elegans. Nature 368: 32-38.

Yue, L. and A.C. Spradling. 1992. hu-li tai shao, a gene required for ring canal formation during Drosophila oogenesis, encodes a homolog of adducin. Genes \& Dev. 6: 2443-2454.

Zhang, J. and M.P. Deutcher. 1988. Escherichia coli RNase D:
Sequencing of the rnd structural gene and purification of the overexpressed protein. Nucleic Acids Res. 16: 6265-6278.

Zheng, Y., M.L. Wong, B.M. Alberts, and T. Mitchison. 1995. Nucleation of microtubule assembly by a $\gamma$-tubulin-containing ring complex. Nature 378: 578-583. 


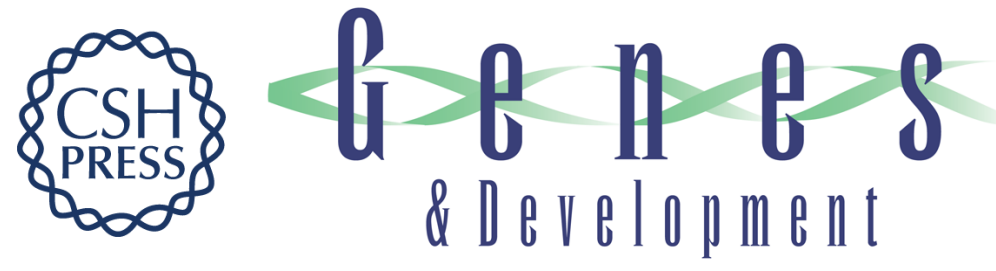

\section{An Egalitarian-BicaudalD complex is essential for oocyte specification and axis determination in Drosophila.}

J M Mach and R Lehmann

Genes Dev. 1997, 11:

Access the most recent version at doi:10.1101/gad.11.4.423

References This article cites 46 articles, 24 of which can be accessed free at: http://genesdev.cshlp.org/content/11/4/423.full.html\#ref-list-1

License

Email Alerting

Service

Receive free email alerts when new articles cite this article - sign up in the box at the top right corner of the article or click here.

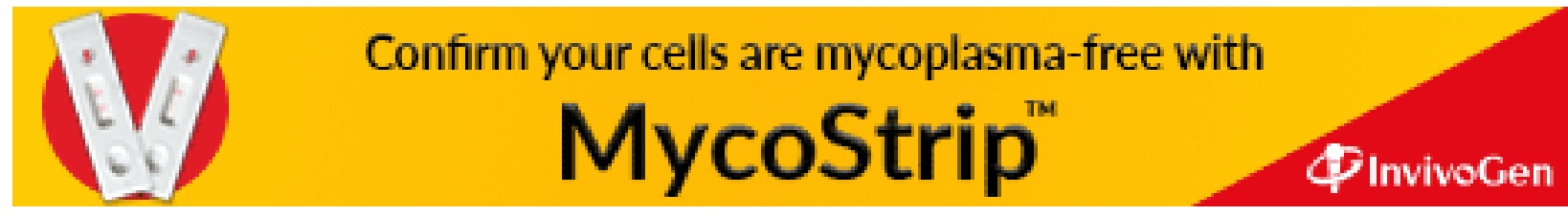

